\title{
Quantifying the resuspension of nutrients and sediment by demersal trawling
}

\author{
Sarah A. Breimann ${ }^{\text {a,b,c, }}$, Finbarr G. O'Neill ${ }^{\text {b, d }}$, Keith Summerbell ${ }^{\text {b }}$, Daniel J. Mayor ${ }^{\text {a }}$ \\ ${ }^{a}$ National Oceanography Centre, European Way, Southampton, England, SO14 3ZH, UK \\ ${ }^{\mathrm{b}}$ Marine Scotland Science, 375 Victoria Rd, Aberdeen, Scotland, AB11 9DB, UK \\ c Plymouth Marine Laboratory, Prospect Place, the Hoe, Plymouth, PL1 3DH, UK \\ d Technical University of Denmark, National Institute of Aquatic Resources, Hirtshals, Denmark
}

\section{A R T I C L E I N F O}

\section{Keywords:}

Fisheries trawling

Gear design

Seabed resuspension

Nutrient concentrations

Particle size distributions

\begin{abstract}
A B S T R A C T
Demersal fisheries trawling is widely acknowledged as one of the most intense forms of widespread benthic disturbance, resuspending extensive plumes of sediments and dissolved nutrients. However, difficulties associated with sampling within trawl plumes have hitherto limited our quantitative understanding of these widespread phenomena. This lack of knowledge hinders our ability to understand the broader consequences of demersal trawling and the development of new fishing gears to limit benthic disturbance. Here we present data from a series of novel in situ experiments using a specially designed trawl sled to quantitatively examine how trawl gear-induced drag and pressure influence the height and concentrations of resuspended sediments and nutrients within a trawl plume. Our data demonstrate that the composition of resuspended particles and sampled nutrients are both influenced by sampling height above the seafloor and the amount of drag exerted by the trawl gear ( $p<0.001$ in all cases), although the relative importance of these factors differed between the response variables examined. These differences likely reflect that sediment particles are more influenced by gravity than dissolved nutrients are. Our results demonstrate that trawl gear specification strongly influences the amount of dissolved and particulate material resuspended, suggesting that their design could be modified to reduce impacts on benthic ecosystems.
\end{abstract}

\section{Introduction}

Shelf sea ecosystems are highly productive, accounting for $\sim 50 \%$ of total ocean primary production (Devol and Christensen, 1993). The remineralization of detrital material at the shelf sea floor plays a pivotal role in supporting benthic and pelagic foodwebs (Fenchel and Jorgensen, 1977; Lennon and Cottingham, 2008) and can account for $100 \%$ of the nutrients available to the production of biomass (Balzer, 1984). Globally, shelf sea production - both benthic and pelagic - supports $90 \%$ of global commercial fisheries (Pauly et al., 2002). However, fishery-related trawling is also the most intense form of benthic disturbance globally (Trimmer et al., 2005) and must be monitored and controlled in order to guarantee that "sea floor integrity ensures functioning of the ecosystem" (DEFRA, 2012; Good Environmental Status Descriptor 6).

Coastal communities are heavily reliant on the integrity of the seafloor, as this provides the majority of the nutrient supply for surface primary production on which global short- and long-term fishing catch maxima are based (Chassot et al., 2007). The annual cumulative trawl-swept area of the 21 ICES management areas between 2010 and 2012 equated to $96 \%$ of the seafloor (Eigaard et al., 2016). Modelled data based on Vessel Monitoring Systems for the same time period predicted that an average of $42 \%$ of the North Sea shelf could be trawled each year and that $86 \%$ of effort is attributable to bottom trawling (Amoroso et al., 2018). Such intense disturbance can lead to physical changes to the local environment and ecology and may also influence the capability of benthic systems to recycle organic matter (Dounas, 2006; Tiano et al., 2019).

Benthic trawl gears are designed to optimise the catch of target species (Eigaard et al., 2016, 2017), typically leaving behind characteristic sedimentary features related to the interaction of the fishing gear and the seabed (Smith et al., 2003). Past studies indicated that heavier

Abbreviations: PSD, Particle Size Distribution; RDA, Redundancy Analysis; GLS, Generalised Least Squares.

* Corresponding author. Plymouth Marine Laboratory, Prospect Place, The Hoe, Plymouth, PL1 3DH, UK.

E-mail address: sabr@pml.ac.uk (S.A. Breimann). 
gears cause deeper furrows and scours resulting in more concentrated trawl plumes (Churchill, 1989). However, more recent studies concluded that this is not necessarily the case and that a lot of the material from these furrows and scours had been compacted or displaced laterally (O'Neill and Summerbell, 2016). Studies on the development of sediment plumes behind towed gears have demonstrated that material within trawl plumes is highly dependent on the turbulence of the wake flow, which is characterised by vortices and eddies formed by the gear, while the quantity of the material resuspended is related to the sediment type and drag introduced by the trawl component (O'Neill and Summerbell 2011; O'Neill and Summerbell, 2016).

Towed demersal gears produce sediment plumes consisting of suspended particulate matter and pore water nutrients (Nilsson and Rosenberg, 2003; (Dounas et al., 2007)) which can be released in high concentrations into the overlying water column (Pilskaln et al., 1998; Couceiro et al., 2013). The size and concentrations of settling particles within a trawl plume decreases with increasing distance from the impact site (O'Neill and Ivanović, 2016), resulting in a filtration effect where the finer particles that are retained within the water column diffuse or are transported away, leaving behind larger, heavier particles (Wengrove et al., 2015). The resulting increased water column turbidity reduces the potential for primary production (Henley et al., 2010). The displacement of particles also strongly affects benthic productivity by changing the sediment type, and the biological community within it (Hale et al., 2017). Modelling of post-trawl sediment biogeochemistry indicated a significant decrease in mineralization rates due to a reduction in annual bioturbation rates (De Borger et al., 2021).

A number of studies have assessed and compared the impacts of different gears, which can inform mitigation strategies to reduce organism mortality and sediment resuspension. Durrieu de Madron et al. (2005) found that muddy sediments in the Gulf of Lion, known for lower nutrient release under natural conditions, resuspended between 2-5 orders of magnitude more nutrients after a trawl pass. Sciberras et al. (2018) indicated that benthic communities in muddy or biogenic sediments are more strongly affected and that the effect was directly related to gear-specific penetration depth. Other studies (Depestele et al., 2016; Rijnsdorp et al., 2017, 2021) demonstrate that the differential impacts of different types of trawl beams can be attributed to design differences.
Tiano et al. (2019) focussed on the biogeochemical repercussions of tickler chain beam trawls and electric PulseWing trawl gears and concluded that the displacement of surficial sediments led to the immediate reduction of benthic metabolism.

The present study aimed to determine how the manipulation of trawl gear design would affect the disturbance of the seafloor. To this end, a specially designed trawl sled was deployed to take measurements of particulate and dissolved material at different heights within the trawl plume. Components of different diameter and weight were used to simulate different categories of hydrodynamic drag and pressure on the sediment. The reconfigurable nature of this novel gear allowed us to quantitatively examine the effects of drag and pressure on the concentrations and height to which nutrients and particulate material were suspended in a trawl plume.

\section{Methods}

All sampling was carried out on board the RV Alba na Mara (Marine Scotland Science) during the summer of 2015 at the Tarbat Ness Hollows site of the outer Moray Firth, Scotland (Fig. 1). Sampling was carried out along the 50-60 m contour (minimum depth $50.8 \mathrm{~m}$, maximum depth $58.4 \mathrm{~m}$ ) in an area which was characterised by muddy sand (28\% mud, $72 \%$ sand respectively).

\subsection{Sampling equipment}

Samples were collected using a custom-made towing sledge $0.9 \mathrm{~m}$ high, $2.1 \mathrm{~m}$ wide, $3.0 \mathrm{~m}$ long and weighing $530 \mathrm{~kg}$. The sledge was equipped with trawl gears of varying dimensions (Fig. 2) and weight combinations $(0 \mathrm{~kg}, 60 \mathrm{~kg}, 120 \mathrm{~kg}$ and $180 \mathrm{~kg}$ ). A vertical array of cylindrical Niskin bottles (internal bottle diameter $=10 \mathrm{~cm}$; length $=38.5$ $\mathrm{cm}$ ) was fixed to the back of the sampling structure $-90 \mathrm{~cm}$ behind a cylindrical trawl component - and were used for sample collection. Niskins were arranged at $25 \mathrm{~cm}, 35 \mathrm{~cm}, 55 \mathrm{~cm}$ and $75 \mathrm{~cm}$ from the sea floor (Fig. 2). A Niskin bottle of the same dimensions was fixed above the trawl component at $75 \mathrm{~cm}-95 \mathrm{~cm}$ (depending on the diameter of the trawl component), to act as a sample control, measuring background concentrations. The trawl gear was deployed and towed along the sea

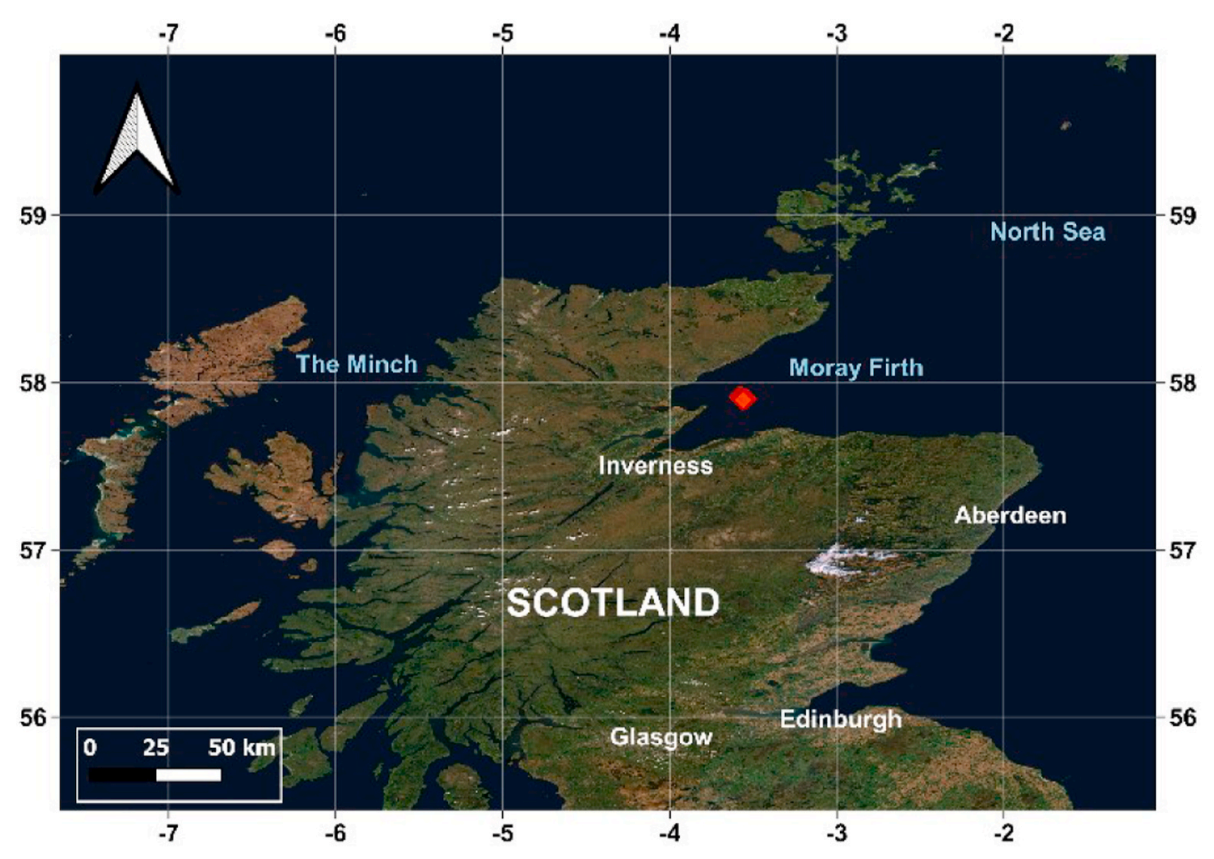

Fig. 1. Map identifying the Hollows sampling site (Tarbat Ness, North of Scotland) shown as a red diamond. Created using the free and open source QGIS software, using the satellite basemap by ESRI: ESRI. "Satellite" [basemap]. Scale 1:123923. "World Imagery". May 19, 2021. https://server.arcgisonline. com/ArcGIS/rest/services/World_Imagery/MapServer/tile/\{z\} $/\{\mathrm{y}\} /\{\mathrm{x}\}$. (08 June 2021). 

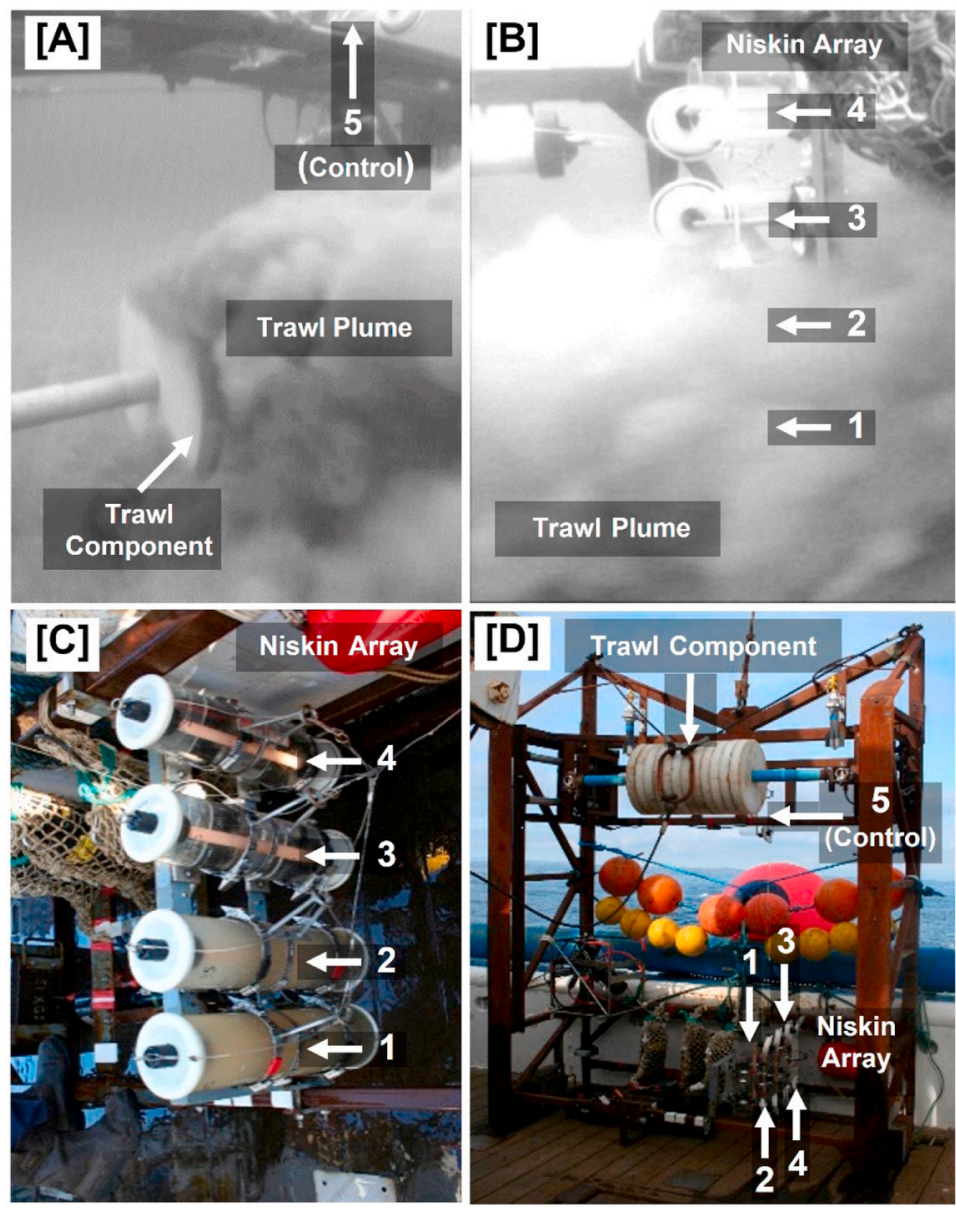
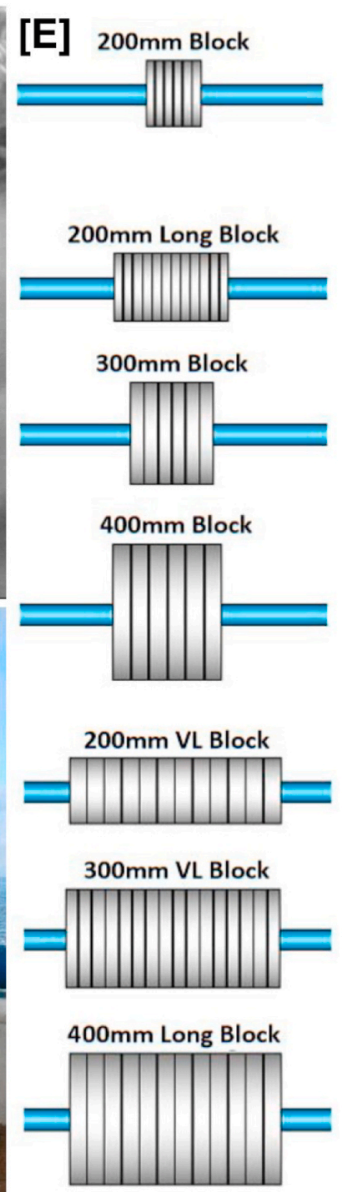

Fig. 2. Visualisation of sampling equipment mounted onto the custom-made experimental sledge designed for plume water sample collection. [A] Plumes and eddies as created by the cylindrical trawl component and the positioning of the control bottle (arrow 5) out-with the trawl plume in the top right of the image, [B] trawl plume and the eddies therein passing through open Niskin bottles highlighted by arrows numbered as $1,2,3$ and 4 to represent sample Niskins collecting plume water samples at $25 \mathrm{~cm}, 35 \mathrm{~cm}, 55 \mathrm{~cm}$ and $75 \mathrm{~cm}$ from the sealfloor, respectively, [C] closed Niskin bottles containing the retrieved plume samples, [D] sampling sledge stood on end showing position of the trawl component, control Niskin (bottle 5) and Niskin array (bottles 1 to 4). Panel [E] presents the trawl component dimensions used in this study; 200 Block gear dimensions: $0.2 \mathrm{~m}$ diameter, 0.15m long, Low drag; 200 Long Block dimensions: $0.2 \mathrm{~m}$ diameter, $0.3 \mathrm{~m}$ long, Low drag; 300mm (300 Block) gear dimensions: $0.3 \mathrm{~m}$ diameter, $0.225 \mathrm{~m}$ long, Medium drag; 400mm (400 Block) gear dimensions: 04.m diameter, $0.3 \mathrm{~m}$ long, High drag; 200VL600 Block dimensions: $0.2 \mathrm{~m}$ diameter, $0.6 \mathrm{~m}$ long, Low drag; 300VL600 Block dimensions: $0.3 \mathrm{~m}$ diameter, $0.6 \mathrm{~m}$ long, Medium drag; 400 Long Block dimensions: $0.4 \mathrm{~m}$ diameter, $0.6 \mathrm{~m}$ long, High drag. floor at 3 knots. The sampling rig was successfully deployed testing all trawl gear and weight combinations. A gear control was introduced by raising the trawl gear above the sediment without additional weights attached - this will henceforth be referred to as the "no contact" treatment. While the no contact treatments did not physically touch the seafloor, it is possible that its turbulent wake may have resuspended particles in samples collected in lower sampling Niskins. Each trawl was deployed for $30 \mathrm{~min}$, with Niskins fired at minute 15 via an acoustic release mechanism. Samples remained inside Niskins for approximately 30 min while the rig was hauled on deck. Samples were immediately taken, after being mixed for homogeneity. Table 1 details replication and data availability for each treatment.

\subsection{Sample collection}

Sediment type within the study area was characterised using nine independent deployments of a medium Van Veen sediment grab in a $3 \mathrm{x}$ 3 matrix. Triplicate $50 \mathrm{ml}$ nutrient samples were collected from each Niskin bottle as soon as the gear was retrieved on deck. Dissolved nutrient samples were taken from halfway down the bottle using a syringe and filtered into pre-rinsed $50 \mathrm{ml}$ centrifuge tubes via a $0.2 \mu \mathrm{l}$ polyethersulfone membrane filter and stored at $-20{ }^{\circ} \mathrm{C}$. The water remaining inside the Niskin bottles was re-homogenised by pumping 6 times with a syringe prior to collecting a $0.5 \mathrm{~L}$ sample to quantify the suspended particulate matter.

\subsection{Sample analysis}

Grab-retrieved sediments were collected to categorise sediment types of the sampling sites and were analysed using a Malvern
Instruments Mastersizer E particle analyser by the Benthic Group at Marine Scotland Science, Aberdeen, Scotland.

Concentrations of nitrate $\left(\mathrm{NO}_{3}{ }^{-}\right)$, nitrite $\left(\mathrm{NO}_{2}{ }^{-}\right)$, ammonium $\left(\mathrm{NH}_{4}{ }^{+}\right)$, dissolved silica $\left(\mathrm{SiO}_{2}{ }^{4-}\right)$ and phosphate $\left(\mathrm{PO}_{4}{ }^{3-}\right)$ within each sample were determined using the AA3 nutrient analyser by SEAL Analytical GmbH, Germany.

Particle size distributions (PSDs) of the collected water samples were determined using a Laser In-situ Scattering Transmissiometry instrument by Sequoia Scientific, USA (LISST 100x, Type C). Particle size categories ranged from X1 to X32 $(2.5 \mu \mathrm{m}-500 \mu \mathrm{m}$, respectively; Supplementary Table 1) and were analysed as Mean Volume Concentration of Particles $\left(\mu \mathrm{LL}^{-1}\right)$ as outlined by Sequoia Scientific for the LISST 100x. A peristaltic pump, working at a flow rate of $1850 \mathrm{ml} \mathrm{min}^{-1}$ pumped the sample through the LISST optical path and back into the top of the sample cylinder. Highly concentrated samples which were not measurable, were diluted with Milli-Q water until readable levels were reached. A "zscat" (background concentration) profile was established with Milli$\mathrm{Q}$ water before each measurement. One sample measurement consisted of 150 output frames, taken while the sample was pumped in front of the detector through an optical insert. Samples were poured into a purposemade Perspex cylinder connected to an $8 \mathrm{~mm}$ bore tube fixed at the halfway level of the sample cylinder. A magnetic stirrer ensured mixing of particles within the sample. If dilutions were required, samples were mixed at the highest spin setting so that heavier particles remained in suspension. The sample was decanted into two clean sampling bottles, which were alternated every 2 seconds to reduce error. After each measurement, the system was flushed with tap water to remove all particles, then flushed twice more with Milli-Q water. Once all samples for a run were collected, the data were averaged across the 150 frames and corrected according to the dilutions. 
Table 1

Replication of each treatment level and the number of samples (n) collected to explore the effects of drag on [A] drag $\left(\mathrm{Nm}^{-1}\right)$, [B] sampling height (cm) and [C] pressure $\left(\mathrm{Nm}^{-2}\right)$ on resuspended particulate and nutrient concentrations.

\begin{tabular}{|c|c|c|}
\hline \multicolumn{3}{|l|}{ [A] Drag } \\
\hline Level & Replication & $\mathrm{n}=$ \\
\hline High & 6 & 30 \\
\hline Medium & 9 & 43 \\
\hline Low & 7 & 35 \\
\hline No contact & 8 & 40 \\
\hline Total & 30 & 148 \\
\hline \multicolumn{3}{|c|}{ [B] Sampling height } \\
\hline Level & Replication & $\mathrm{n}=$ \\
\hline Control & 6 & 30 \\
\hline $75 \mathrm{~cm}$ & 6 & 29 \\
\hline $55 \mathrm{~cm}$ & 6 & 29 \\
\hline $35 \mathrm{~cm}$ & 6 & 30 \\
\hline $25 \mathrm{~cm}$ & 6 & 30 \\
\hline Total & 30 & 148 \\
\hline \multicolumn{3}{|c|}{ [C] Pressure } \\
\hline Level & Replication & $\mathrm{n}=$ \\
\hline 0 & 8 & 40 \\
\hline 2450 & 1 & 5 \\
\hline 3266.67 & 1 & 5 \\
\hline 4355.56 & 1 & 5 \\
\hline 4900 & 3 & 15 \\
\hline 6533.33 & 1 & 5 \\
\hline 7350 & 1 & 5 \\
\hline 8711.11 & 2 & 8 \\
\hline 9800 & 4 & 20 \\
\hline 13066.67 & 1 & 5 \\
\hline 14700 & 2 & 10 \\
\hline 17422.22 & 1 & 5 \\
\hline 19600 & 1 & 5 \\
\hline 26133.33 & 1 & 5 \\
\hline 29400 & 1 & 5 \\
\hline 39200 & 1 & 5 \\
\hline Total & 30 & 148 \\
\hline
\end{tabular}

Particle size delimitations used by the SEQUOIA LISST were determined by an array of 32 logarithmically increasing concentric rings and the detection of 32 angles of laser diffraction by the detector (Agrawal and Pottsmith, 2000). These were then related to particle volumes as determined by the Wentworth scale (Wentworth, 1922) and were further separated to represent sediment types as described by Blott and Pye (2012) (Supplementary Table 1). Data within each category reported by the LISST-100X were logarithmically related to the previous and sequential category.

To supplement analysis of absolute PSD data and explore proportional differences between grab and plume samples, each of the 32 subcategories of a sample were converted to a percentage, calculated from the total concentration within that sample. Data collected from control samples were not included in comparisons between grab sample particulates and plume particulates.

\subsection{Data analysis}

The hydrodynamic drag per unit width, $D\left(\mathrm{Nm}^{-1}\right)$, and the pressure, $p\left(\mathrm{Nm}^{-2}\right)$, for each gear type and weight combination were calculated as follows:

Equation (1):

$$
D=0.5 \rho U^{2}(0.64) d
$$

Equation (2):

$$
p=m g /(d w)
$$

where $\rho$ is the density of water $\left(\mathrm{kgm}^{-3}\right), U$ is the towing speed $\left(\mathrm{ms}^{-1}\right)$, $d$ is the disk diameter (m), $m$ is the mass of the trawl gear cylinder $(\mathrm{kg}), g$ is gravity $\left(\mathrm{ms}^{-2}\right)$ and $w$ is the gear width (O'Neill and Summerbell, 2016). The 0.64 in the first equation is the drag coefficient which is a dimensionless quantiy that characterises the hydrodynamic drag for cylindrical gears with a width to diameter ratio $>0.2$ (O'Neill et al., 2018). Drag levels in this study were simulated using trawl components of different diameters (i.e. varying $d$ in Equation (1)) (Fig. 2E), while the pressure exerted on the sea floor was obtained both by adding weights to the trawl sledge and using trawl components of different diameters and widths (i.e. varying $m, d$ and $w$ in Equation (2)).

PSDs of the trawl plume water samples and the underlying sediments were compared after converting the observed concentrations into percentages of the sample total.

Redundancy analysis (RDA) was used to examine how sampling height, drag and pressure influenced PSD, nutrient concentrations and PSD and nutrient concentrations combined. For individual analyses, PSD data were Hellinger transformed to meet the assumptions of normality (Legendre and Gallagher, 2001), while nutrient data were left untransformed (Supplementary Figs. 1-4 for exploration plots of PSD concentration data, Supplementary Figs. 6-20 for assumption testing of nutrient data). Sampling height and drag were treated as factorial variables, whereas pressure was treated as a continuous variable. Due to the relationship between drag and pressure and sampling constraints which meant that replication of pressure levels ranged from $n=5$ to $n=40$, model selection did not include interactive effects to reduce erroneous significance. Analysis of combined nutrients and PSDs required data to be converted into percentages to combine and normalise the data prior to analysis. The significance of each term within the RDA model was determined by a permuted $(n=9999)$ forward selection procedure (Mayor et al., 2013).

The influence of drag, pressure and sampling height on the concentrations of individual nutrients were also examined using linear regression (Generalised Least Squares; GLS) of untransformed data using a backwards selection technique (Mayor and Solan, 2011). Hydrodynamic drag categories were fitted as factors within this study and were referred to as: no contact for the case when the component was held above the seafloor; and low $\left(152.44 \mathrm{Nm}^{-1}\right)$, medium $\left(228.66 \mathrm{Nm}^{-1}\right)$ and high drag $\left(304.88 \mathrm{Nm}^{-1}\right)$ for the cases where the component was on the sea floor and produced these respective hydrodynamic drag values per meter width. It is important to note that our level terms (low, medium, high) are relative to our study only, i.e., high drag in this study does not necessarily relate to the highest drag fishing gears within the industry, rather, it is the highest level of drag examined in this study.

All data were analysed using the $\mathrm{R}$ statistical package version 3.4.0. (R Core Team.R, 2014) using the 'vegan' (Oksanen et al., 2013), 'nlme' (Pinheiro et al., 2017) and 'olsrr' (Hebbali, 2020) packages.

\section{Results}

\subsection{Particle size distributions of sediment grab and plume water samples}

The relative abundance of particles observed in both plume waters (combined treatments, minus the sampling height control) and grab samples increased between $25.39 \mu \mathrm{m}$ and $95.48 \mu \mathrm{m}$ size classes (Fig. 3), followed by a decrease in both from $95.48 \mu \mathrm{m}$ to $156.90 \mu \mathrm{m}$. The observed variability in the percentage contributions of particles $\geq 218.49 \mu \mathrm{m}$ remained low in the grab sample data (Fig. 3A), whereas a steep increase in the variance of these particles became apparent in plume water samples, representing up to $63 \%$ of $423.70-500.00 \mu \mathrm{m}$ particle size class in some samples. However, median values between sediment grab and plume water samples appeared similar (Fig. 3B).

Plume water sample percentage plots for data collected at $25 \mathrm{~cm}, 35$ $\mathrm{cm}, 55 \mathrm{~cm}$ and $75 \mathrm{~cm}$ from the seafloor generated similar distributions for particles between $2.50 \mu \mathrm{m}$ and $156.90 \mu \mathrm{m}$, with differences in relative abundances emerging in samples collected $>35 \mathrm{~cm}$ and in particles $>156.90 \mu \mathrm{m}$ (Fig. 4). Percentage contributions of each size category 

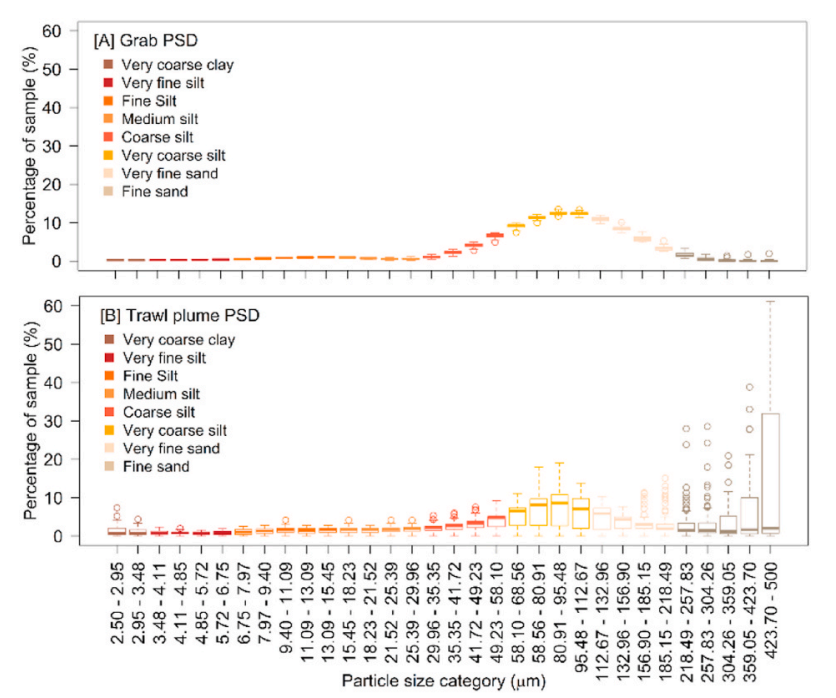

Fig. 3. [Colour]: Percentage particle size distribution (PSD) data for all samples collected within trawl plumes and in grab samples. Boxplots were colour coded according to the particle size fractionation outlined by Blott and Pye (2012); associated sediment sizing is outlined in Supplementary Table 1. [A] - Percentages of PSD data of grab samples obtained by analysis with a Malvern Instruments Mastersizer E particle analyser. [B] Percentages of PSD data collected within trawl plume water samples obtained via a SEQUOIA LISST 100X Type C.

between $2.50 \mu \mathrm{m}$ and $156.90 \mu \mathrm{m}$ indicated very similar maximum to minimum ranges in variability, however the median values for PSD categories in the peak became more reduced at $\geq 55 \mathrm{~cm}$. Control samples and data collected at $75 \mathrm{~cm}$ had very similar distributions, with the same peak forming between $29.96 \mu \mathrm{m}$ and $156.90 \mu \mathrm{m}$, and a second peak between $156.90 \mu \mathrm{m}$ and $500.00 \mu \mathrm{m}$, with over $60 \%$ of some samples accounted for in particles sized between $423.70 \mu \mathrm{m}$ and $500.00 \mu \mathrm{m}$ (Fig. 4).

\subsection{Particle size distributions and the influence of drag, sampling height} and pressure

Fig. 5 presents particle size distributions (mean volume concentration $\mu \mathrm{LL}^{-1}$ ) in water samples collected from trawl plumes of different drag treatments and at different sampling heights; see Supplementary Fig. 1 and Supplementary Fig. 2 for sampling height and drag plotted separately.

The $80.91 \mu \mathrm{m}-95.48 \mu \mathrm{m}$ particle size category consistently registered the highest concentrations for each treatment. The smallest particle concentration peak was measured in no contact samples at 199.70 $\mu \mathrm{LL}^{-1}$, whereas the largest was measured in medium drag samples at 25 $\mathrm{cm}$ from the seafloor, registering $2993.90 \mu \mathrm{LL}^{-1}$. Low drag samples were the second most concentrated, with a peak of $2444.40 \mu \mathrm{LL}^{-1}$. Of all the disturbance treatments, high drag displayed the lowest concentration peak with a measurement of $1258.90 \mu \mathrm{LL}^{-1}$.

As sampling height increased, particle concentrations were reduced. Samples collected $25 \mathrm{~cm}$ from the sea floor had the highest concentrations $\left(2993.90 \mu \mathrm{LL}^{-1}\right)$. The highest particle concentrations at $35 \mathrm{~cm}$, $55 \mathrm{~cm}$ and $75 \mathrm{~cm}$ were $1142.90 \mu \mathrm{LL}^{-1}, 1099.80 \mu \mathrm{LL}^{-1}$ and $27.20 \mu \mathrm{LL}^{-1}$, respectively. Sampling height exhibited the highest variation in particle size distributions, which decreased as sampling height increased.

Increased pressure on the sea floor did not display any trends in PSDs in trawl plume water samples, however the shoulders of the concentration peaks were consistently spread across particle sizes ranging from $13.09 \mu \mathrm{m}$ to $218.49 \mu \mathrm{m}$, suggesting a uniform sediment type (Supplementary Fig. 3).

Plume water samples collected $75 \mathrm{~cm}$ from the seafloor and the control samples registered almost the same maximum PSD
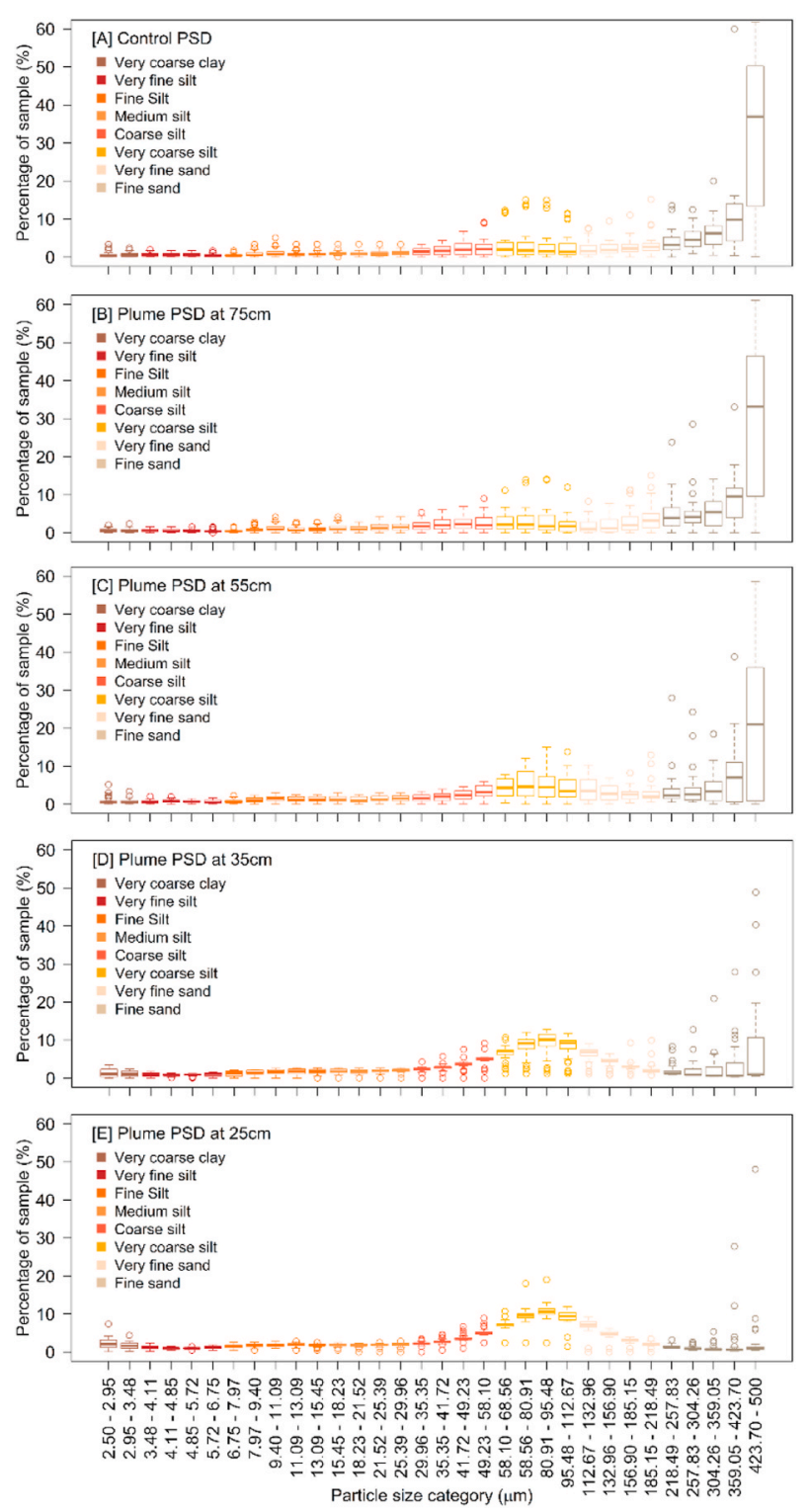

Fig. 4. [Colour]: Percentage particle size distribution (PSD) data for plume samples separated by sampling height which are from top to bottom: [A] Control, [B] $75 \mathrm{~cm}$, [C] $55 \mathrm{~cm}$, [D] $35 \mathrm{~cm}$ and [E] $25 \mathrm{~cm}$. Boxplots were colour coded according to the particle size fractionation outlined by Blott and Pye (2012); associated sediment sizing is outlined in Supplementary Table 1.

concentration (27.20 $\mu \mathrm{LL}^{-1}$ and $26.6 \mu \mathrm{LL}^{-1}$, respectively), while combined data for no contact treatments registered concentrations between $0.00 \mu \mathrm{LL}^{-1}$ and $199.70 \mu \mathrm{LL}^{-1}$, while the maximum concentrations of low, medium, and high drag treatments registered as $2444.40 \mu \mathrm{LL}^{-1}$, $2993.9 \mu \mathrm{LL}^{-1}$ and $1258.90 \mu \mathrm{LL}^{-1}$, respectively. Both sampling height control and no contact treatments were determined suitable for use as a control in analyses. Fig. 5 presents particle size distributions (Mean volume concentration in $\mu \mathrm{LL}^{-1}$ ) of samples with data organised by sampling height and drag.

Particle size distributions were significantly influenced by sampling height and demonstrated a difference in composition spanning across the origin between samples collected $\leq 35 \mathrm{~cm}$ and those collected $>35 \mathrm{~cm}$, including the control $(\mathrm{RDA}$; $\mathrm{Df}=4, \mathrm{~F}=11.35, \mathrm{p}=0.001$, Supplementary Figs. 4A and B). The level of drag exerted by the trawl component also significantly affected PSD concentrations, with samples from no contact and medium drag treatments exhibiting the strongest variation $(\mathrm{RDA} ; \mathrm{Df}=3, \mathrm{~F}=2.80, \mathrm{p}=0.004$, Supplementary Figs. $4 \mathrm{C}$ and 

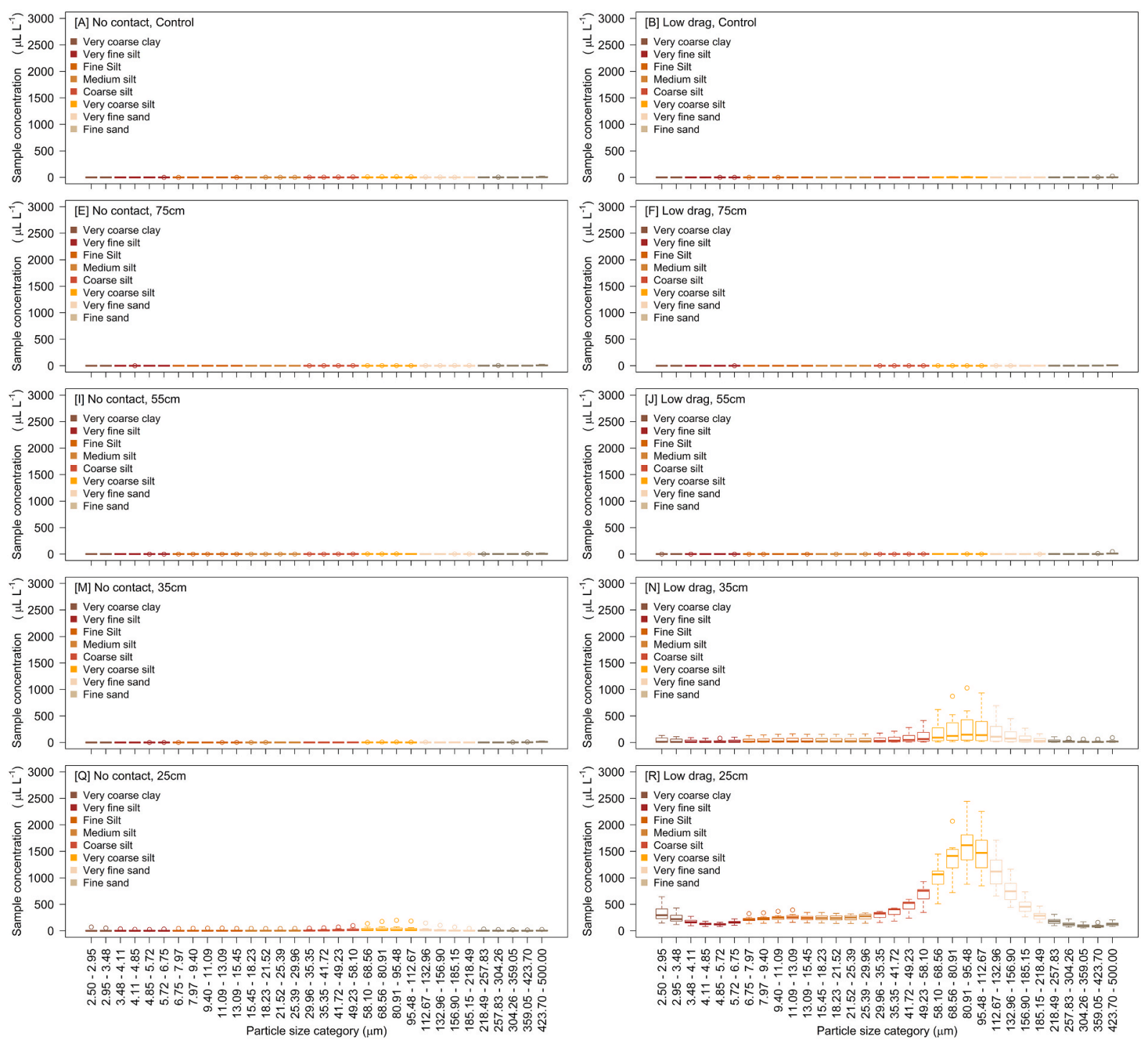

Fig. 5. [Colour]: Untransformed particle size distributions (Mean Volume Concentration of Particles $\left(\mu \mathrm{LL}^{-1}\right)$ ) for no contact and low drag across all sampling heights. Plots show 32 particle categories representing size bins of $2.50 \mu \mathrm{m}-500.00 \mu \mathrm{m}$ and were coloured to show sediment type (Supplementary Table 1; Blott and Pye (2012)). [Left to right] No contact, low drag, medium drag and high drag data. [Bottom to top] Increasing distance from the seafloor: $25 \mathrm{~cm}, 35 \mathrm{~cm}, 55 \mathrm{~cm}$, $75 \mathrm{~cm}$ and control.

Fig. 5 continued [Colour]: Untransformed particle size distributions (Mean Volume Concentration of Particles $\left(\mu \mathrm{LL}^{-1}\right)$ ) for no contact and low drag across all sampling heights. Plots show 32 particle categories representing size bins of $2.50 \mu \mathrm{m}-500.00 \mu \mathrm{m}$ and were coloured to show sediment type (Supplementary Table 1 ; Blott and Pye (2012). [Left to right] No contact, low drag, medium drag and high drag data. [Bottom to top] Increasing distance from the seafloor: $25 \mathrm{~cm}$, $35 \mathrm{~cm}$, $55 \mathrm{~cm}, 75 \mathrm{~cm}$ and control.

D). Pressure did not significantly affect PSDs (RDA; Df $=1, \mathrm{~F}=0.57, \mathrm{p}=$ 0.645). The RDA explained $33.00 \%$ of variation in the PSD data, with sampling height and drag accounting for $28.73 \%$ and $4.32 \%$, respectively (Supplementary Fig. 4; Supplementary Table 2 includes the full model output).

\subsection{Dissolved nutrient concentrations and the influence of drag, sampling height and pressure}

Total measured nitrate $\left(\mathrm{NO}_{3}{ }^{-}\right)$concentrations ranged between 0.10 $\mu \mathrm{molL}^{-1}$ to $1.39 \mu \mathrm{molL}^{-1}$ (no contact samples ranged between 0.10 $\mu \mathrm{molL}^{-1}$ and $1.24 \mu \mathrm{molL}^{-1}$ ), while nitrite $\left(\mathrm{NO}_{2}{ }^{-}\right.$) concentrations ranged from below the limit of detection to $0.15 \mu \mathrm{molL}^{-1}$ (no contact samples ranged between the detection limit and $0.15 \mu \mathrm{molL}^{-1}$ ). Background concentrations of dissolved nutrients tended to be lower and exhibited more variation than in samples collected as part of a treatment (Figs. 6 and 7). Concentrations of $\mathrm{NO}_{3}{ }^{-}$and $\mathrm{NO}_{2}{ }^{-}$both increased significantly as a function of drag $\left(\mathrm{NO}_{3}{ }^{-} \mathrm{GLS} ; \mathrm{Df}=1, \mathrm{~F}=30.39, \mathrm{p}=0.0001, \mathrm{NO}_{2}{ }^{-} \mathrm{GLS}\right.$; $\mathrm{Df}=1, \mathrm{~F}=8.54, \mathrm{p}=0.004$; Fig. 6A-B; Supplementary Tables 3 and 4, respectively), while sampling height and pressure were dropped during the GLS model selection process $\left(\mathrm{NO}_{3}{ }^{-}\right.$GLS model selection: Sampling height $\mathrm{p}=0.837$, Pressure $\mathrm{p}=0.321, \mathrm{NO}_{2}{ }^{-}$GLS model selection: Sampling height $\mathrm{p}=0.969$, Pressure $\mathrm{p}=0.415$; Supplementary Tables 3 and 4, respectively). High drag data indicated much higher release of $\mathrm{NO}_{3}{ }^{-}$than for other drag levels, however the slope of the regression was reduced due to the high variability observed in medium drag. This result likely emerges because a) there is a lot of variability in the medium drag treatment, in part because there are more observations, and b) there are also the fewest number observations at the highest level of drag.

Phosphate $\left(\mathrm{PO}_{4}{ }^{3-}\right)$ concentrations ranged from $0.08 \mu \mathrm{molL}^{-1}$ to 

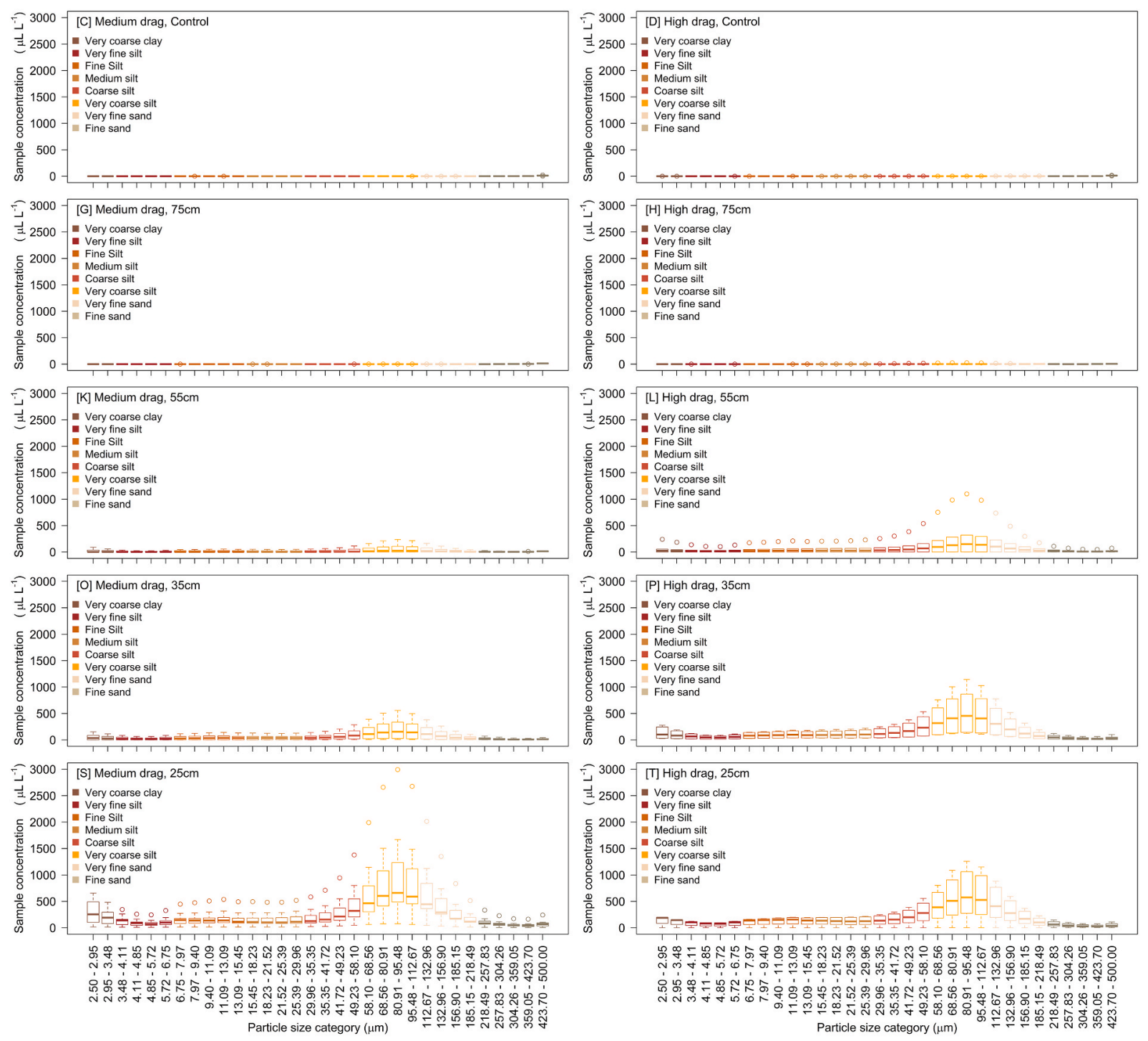

Fig. 5. (continued).

$0.99 \mu \mathrm{molL}^{-1}$ with no contact samples ranging between 0.08 and 0.54 $\mu$ molL ${ }^{-1}$. Concentrations of $\mathrm{SiO}_{2}{ }^{4-}$ varied between $0.12 \mu \mathrm{molL}^{-1}$ and $6.15 \mu \mathrm{molL}^{-1}$ with no contact samples ranging between 0.12 and 3.61 $\mu$ molL ${ }^{-1}$. Concentrations of $\mathrm{PO}_{4}{ }^{3-}$ and $\mathrm{SiO}_{2}{ }^{4-}$ within trawl plume water samples increased significantly with increasing proximity to the sea floor $\left(\mathrm{PO}_{4}{ }^{3-} \mathrm{GLS}\right.$; $\mathrm{Df}=4, \mathrm{~F}=24.71, \mathrm{p}<0.0001 ; \mathrm{SiO}_{2}{ }^{4-} \mathrm{GLS}$; $\mathrm{Df}=4, \mathrm{~F}=$ $14.80, \mathrm{p}=<0.001)$ and increasing drag exerted by the trawl gear $\left(\mathrm{PO}_{4}{ }^{3-}\right.$ $\mathrm{GLS}$; Df $=1, \mathrm{~F}=22.25, \mathrm{p}=<0.0001, \mathrm{SiO}_{2}{ }^{4-} \mathrm{GLS} ; \mathrm{Df}=1, \mathrm{~F}=17.8, \mathrm{p}=$ $<0.0001$ ) (Fig. 6C-D; Supplementary Tables 5 and 6, respectively). Pressure did not significantly affect $\mathrm{PO}_{4}{ }^{3-}$ or $\mathrm{SiO}_{2}{ }^{4-}$ and were removed from the GLS model during the selection process $\left(\mathrm{PO}_{4}{ }^{3-}\right.$ GLS model selection: Pressure; $\mathrm{Df}=7, \mathrm{~F}=2.57, \mathrm{p}=0.109, \mathrm{SiO}_{2}{ }^{4-}$ GLS model selection: $\mathrm{Df}=7, \mathrm{~F}=0.96, \mathrm{p}=0.326$; Supplementary Tables 5 and 6 , respectively).

Ammonium $\left(\mathrm{NH}_{4}{ }^{+}\right)$concentrations ranged from $0.22 \mu \mathrm{mol} \mathrm{L} \mathrm{L}^{-1}$ to $3.98 \mu \mathrm{mol} \mathrm{L}^{-1}$ with no contact samples ranging between $0.00 \mu \mathrm{mol} \mathrm{L}^{-1}$ and $3.04 \mu \mathrm{mol} \mathrm{L}{ }^{-1}$. Concentrations of $\mathrm{NH}_{4}{ }^{+}$increased significantly with increased proximity to the seafloor and pressure (GLS Sampling height: $\mathrm{Df}=4, \mathrm{~F}=4.32, \mathrm{p}=0.001$; Pressure: $\mathrm{Df}=1, \mathrm{~F}=12.98, \mathrm{p}=0.0004$; Fig. 7; Supplementary Table 7), but were not affected by drag (Df $=7, \mathrm{~F}$ $=0.89, \mathrm{p}=0.345$, Supplementary Table 7).

The relative composition of the observed nutrients was significantly influenced by the level of drag (RDA; $\mathrm{Df}=3, \mathrm{~F}=12.36, \mathrm{p}=0.001)$ and sampling height (RDA; $\mathrm{Df}=4, \mathrm{~F}=6.47, \mathrm{p}=0.001$ ), but not pressure (RDA; $\mathrm{Df}=1, \mathrm{~F}=1.13, \mathrm{p}=0.328$ ). The RDA model explained $35.50 \%$ of the variation, of which drag and sampling height accounted for 15.41 $\%$ and $20.09 \%$, respectively. There was a progressive shift from the no contact samples (grey points), through low (green points) and medium drag (blue points), to the high drag treatment (red points). The effect of sampling height was constrained within RDA2 (Supplementary Figs. 20B and 20C), with particularly strong negative loadings for samples collected at $25 \mathrm{~cm}$ above the seafloor, and positive loadings for the control samples and those collected at $75 \mathrm{~cm}$. It was apparent that the latter two categories were most similar, while samples from $25 \mathrm{~cm}$ were separated out from the rest. Site scores suggested no affinity for any nutrients with any explanatory variables, except for $\mathrm{NO}_{2}{ }^{-}$, which was positioned close to the control and $75 \mathrm{~cm}$, as well as to the origin.

3.4. The influence of sampling height, drag and pressure on all measured variables

Relative abundances of particle size classes and dissolved nutrients within the plume water samples was dependant on the additive effects of sampling height $(\mathrm{Df}=4, \mathrm{~F}=9.84, \mathrm{p}=0.001)$ and drag $(\mathrm{Df}=3, \mathrm{~F}=4.71$, $\mathrm{p}=0.001$ ) but were not affected by the pressure on the seafloor ( $\mathrm{Df}=1$, $\mathrm{F}=0.17, \mathrm{p}=0.61$; Fig. 8, Supplementary Table 9). The model explained 

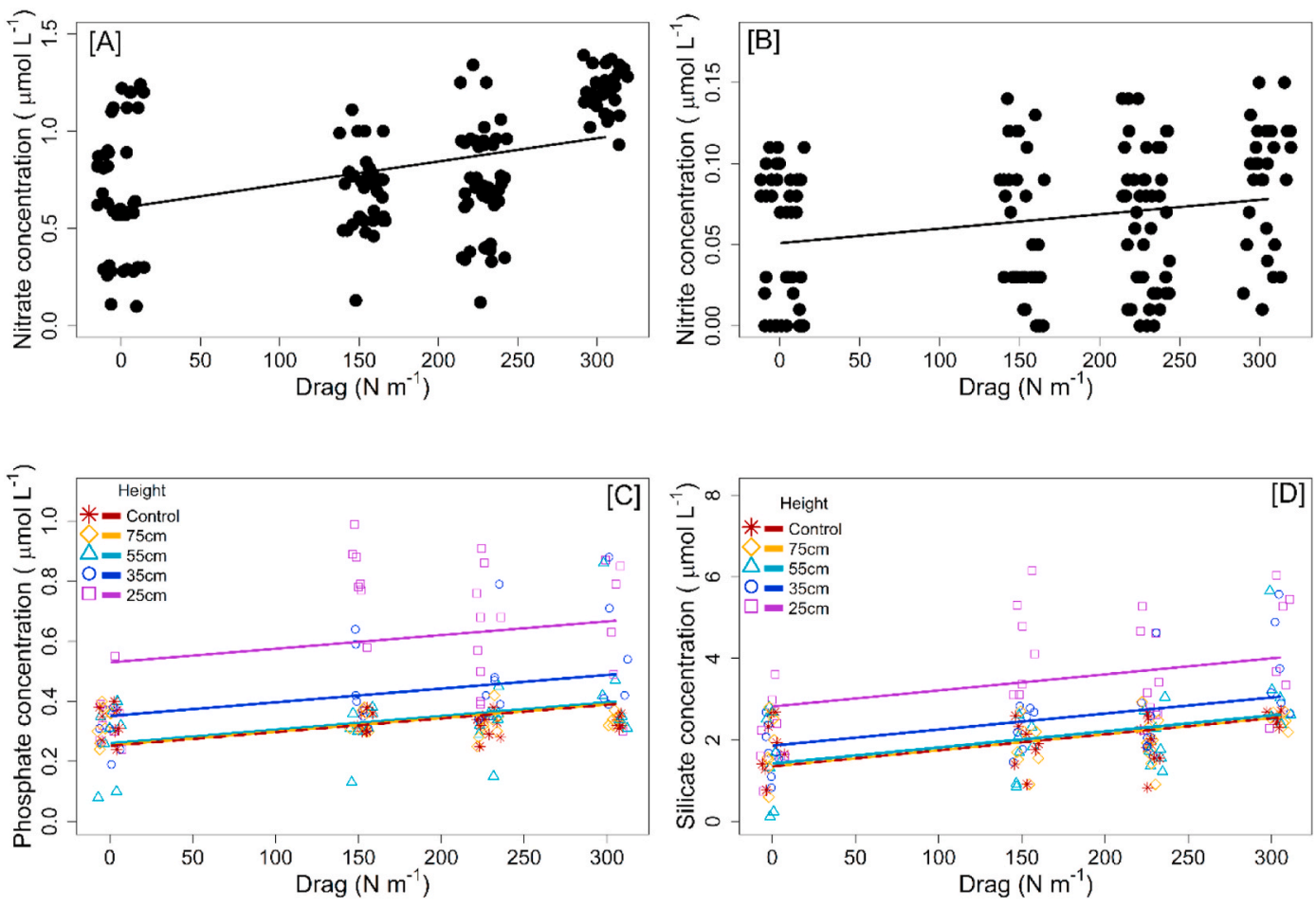

Fig. 6. [Colour] : Graphical representation of nitrate $[A]$, nitrite $[B]$, phosphate $[C]$ and silicate $[D]$ concentrations within trawl plume water samples of four levels of drag; No contact (jittered around $0 \mathrm{Nm}^{-1}$ for clarity, low drag (jittered around $152.44 \mathrm{Nm}^{-1}$ for clarity), medium drag (jittered around $228.66 \mathrm{Nm}{ }^{-1}$ for clarity), high drag (jittered around $304.88 \mathrm{Nm}^{-1}$ for clarity). Data points in panels [C] and [D] are coloured and shaped according to the height of the Niskin bottle sampled. The trends predicted generalised least squares (GLS) were represented by a black line for drag or colour coded according to sampling height, depending on model significance.

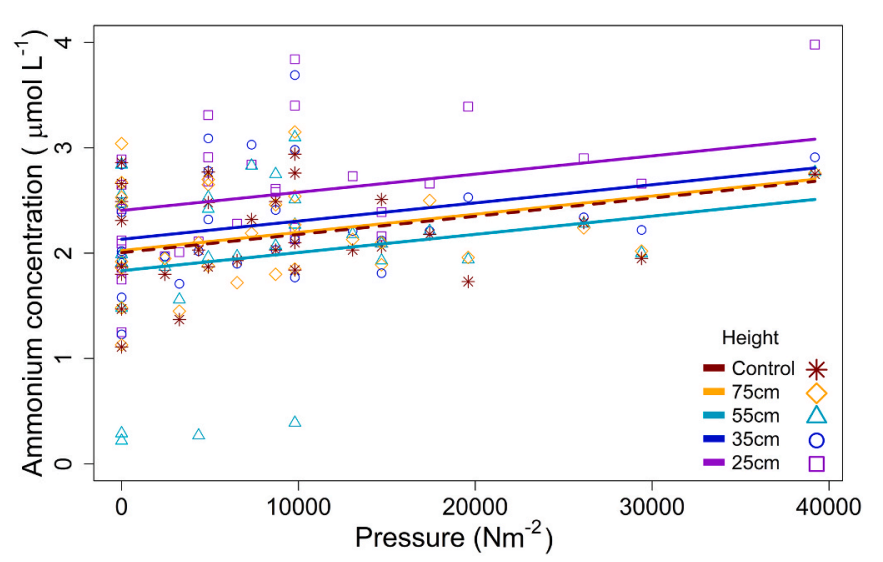

Fig. 7. [Colour] : Increasing trend of ammonium with increasing pressure on the seafloor. Data points are shaped and coloured according to the height of the Niskin bottle sampled. The generalised least squares (GLS) derived predicted trends were colour coded according to height.

$32.86 \%$ of the variation of which sampling height and drag accounted for $26.01 \%$ and $6.85 \%$ respectively. Samples of all drag categories collected at $\leq 35 \mathrm{~cm}$ from the seafloor were restricted to the negative of RDA1, while data obtained from samples collected $\leq 35 \mathrm{~cm}$ were generally plotted across the origin and to the positive of RDA1 (Fig. 8A \& B). Drag effects were discriminated across RDA2, with a strong, positive loading in the high drag treatment, and more negative loadings for the lower drag levels (Fig. 8B \& C). The additive effect could be observed in the strong grouping of high data along RDA2 spanning all sampling heights, indicating additional variation when drag effects were accounted for. The PSD data form 2 main clusters (small particle size classes; X1-X26; $2.50 \mu \mathrm{m}-156.90 \mu \mathrm{m}$ and large particle size classes; X27-
X32; $185.15 \mu \mathrm{m}-500.00 \mu \mathrm{m}$ ) with category X26 placed close to the origin and positioned between the two particle size clusters. $\mathrm{NH}_{4}{ }^{+}$and $\mathrm{NO}_{3}{ }^{-}$did not appear to show any strong correlation with any of the PSD categories. $\mathrm{SiO}_{2}{ }^{4-}$ and $\mathrm{PO}_{4}{ }^{3-}$ were positively aligned with the particle size cluster representing smaller particle sizes (Fig. 8D).

\section{Discussion}

This study demonstrates that the drag and/or pressure generated by benthic trawling gears influence the concentrations and composition of re-suspended particles and dissolved nutrients and the height to which they are transported into the water column. Trawl gear-exerted pressure on the sea floor did not appear to significantly influence the concentration or variability of mobilised particulate matter, although it did have a positive influence on concentrations of ammonium. While variation in control, no contact and plume water samples were apparent, concentrations of particulates and dissolved nutrients were higher in the treatment samples. This indicated that any contact of trawl components altered the biogeochemistry of the immediate water column.

\subsection{Particle size distributions of grab samples and trawl plume water samples}

Percentages of PSDs obtained from the Niskin samples and sediment grabs indicated that, in general, the composition of resuspended particles matched the composition of the underlying sediment (Fig. 3). The exception to this was the occurrence of relatively large size categories ( $>157 \mathrm{um}$ ) in the Niskin samples, suggesting the presence of small planktonic organisms and/or sinking detritus. (Fig. 5).

The high values observed in the relative abundance plots related only to plume water data (size categories $156.90 \mu \mathrm{m}-500.00 \mu \mathrm{m}$; Fig. 3) and may be due to signal leakage, as described by (Agrawal et al., 2008). However mean volume PSD concentration data did not show a 

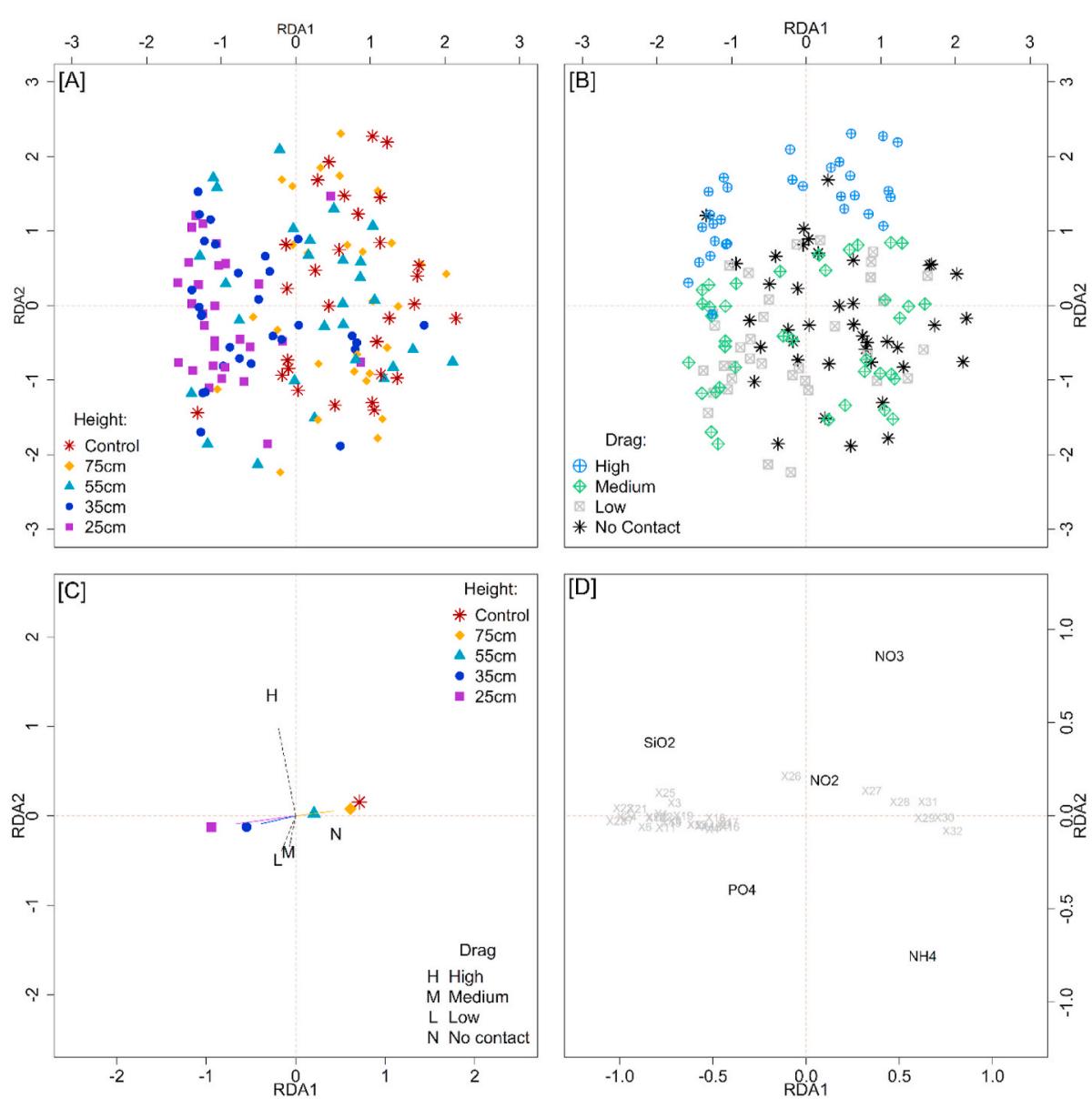

Fig. 8. [Colour]: Redundancy Analysis (RDA) biplots for the combined, relative particle size distributions and nutrient concentrations from trawl plume water samples collected in the Hollows area, Scotland. Panels [A] and [B] present the spread of data colour coded according to sampling height $(\mathrm{cm})$ and drag $\left(\mathrm{Nm}^{-1}\right)$, respectively. Panel [C] is a visualisation of the positioning of centroids (data mean) and biplot scores (directionality and intensity of data) of the explanatory variables - sampling height and drag. Panel [D] illustrates the spread of the response variable - the combined normalised (to percentage) nutrient and particle size distribution data PSD categories are represented as $\mathrm{X}$ numbers which relate to each of the 32 categories outlined in Supplementary Table 1. corresponding increase in the larger size bins (Fig. 5). More likely, this is an artefact of proportional representation, where PSDs of trials resulting in low overall resuspended particulate matter (such as no contact trials) would be weighted equally to trials with components which resuspend high concentrations of partculate matter. In this case, the presence of background particles, e.g. small planktonic organisms, sinking detrital particulates or flocculated particles, would account for a larger proportion of the sample in trawl passes which resuspended the lowest concentrations of particles, resulting in the observed profile. Ultimately, omitting the affected size bins did not significantly change the outcomes of the final RDA model, indicating that the variation is driven by changes between treatments, rather than proportional representation of size classes. The removal of X30 to X32 and X24 to X32 (Supplementary Table 1) resulted in RDA models describing a significant change in PSD concentrations in response to sampling height and drag $(\mathrm{p}=0.001$, in both cases) with no significant effect of pressure.

PSDs were influenced by sampling height and drag, with the sampled quantities of particles decreasing with increasing distance from the seafloor (Fig. 5), while pressure had no effect. These results are consistent with those of O'Neill and Summerbell (2011, 2016), who found that the mobilisation of sediment into the water column behind towed gears is a hydrodynamic process driven by turbulent shearing and the pressure drop in the gears wake and that it is not influenced by the pressure force the gear exerts on the seabed. The height dependency reflects the variability of the turbulence strength and the fact that the more highly accelerated particles will be transported further. O'Neill and Summerbell $(2011,2016)$ also demonstrated that the quantity of sediment mobilised increases with the hydrodynamic drag. We find a similar relationship here in the 35 and $55 \mathrm{~cm}$ bottles, but not in the $25 \mathrm{~cm}$ bottles (Fig. 5; Supplementary Fig. 2). This may be an artefact of taking instantaneous samples in a highly variable environment, where there are areas of high and low turbulence and consequently high and low concentrations of sediment. However, it may also reflect that, even at low drag, the minimum shear stress threshold required to mobilise sediment at this site has been reached, the strength of which is strong enough to raise sediment to the 25 and $35 \mathrm{~cm}$ bottles, but not to a height of $55 \mathrm{~cm}$.

\subsection{Trawling effects on resuspended nutrient concentrations}

Univariate statistical models indicated that increasing drag introduced by different trawl gears had a significant positive effect on all nutrients measured (Fig. 6), except for $\mathrm{NH}_{4}{ }^{+}$, which was affected by increasing pressure (Fig. 7). The energy introduced at each level of drag would be directly relatable to the vortices behind the ground gear, producing areas of high vacuum, drawing porewaters from the sediment. The higher the drag, the stronger the pull from the movement of the vortices over the sediment surface would have been, and the deeper into the sediment the effect would have penetrated, extracting higher concentrations of nutrients. No effect of sampling height was observed in $\mathrm{NO}_{3}{ }^{-}$and $\mathrm{NO}_{2}{ }^{-}$data, as the water bearing the nutrients would follow the vortices through the plume. Redundancy analysis confirmed an additive effect of first drag and then sampling height on the concentrations of nutrients released into the trawl plume. Sampling height accounted for $15 \%$ of the variation in the nutrient dataset and Figs. 6 and 7 indicate that the nutrients affected were $\mathrm{NH}_{4}{ }^{+}, \mathrm{PO}_{4}{ }^{3-}$ and $\mathrm{SiO}_{2}{ }^{4-}$ concentrations. A highly turbid trawl plume would not only contain nutrients and sediment particles but would also be rich in detrital organic matter which would be releasing $\mathrm{NH}_{4}{ }^{+}$as they break down. The continued breakdown of this organic material within Niskin bottles during the 30 min required to haul the gear on deck would cause the graduated height 
effect observed in $\mathrm{NH}_{4}{ }^{+}$concentrations. While the effect of pressure was not retained in the redundancy analysis, univariate analysis determined an increase in $\mathrm{NH}_{4}{ }^{+}$with an increase in pressure. Heavier trawl gears would penetrate further into the sediment which in turn would displace more pore waters and push them into the trawl plume as the trawl gear passes overhead. The effect of pressure may have been retained as the vorticity of drag may not have diluted these concentrations in the same way as $\mathrm{NO}_{3}{ }^{-}$and $\mathrm{NO}_{2}{ }^{-}$were before capture in the sampling Niskins. This is supported by data collected at different sampling heights as concentrations of $\mathrm{NH}_{4}{ }^{+}$were lower towards the top of the plume where the dilution effect would be stronger.

$\mathrm{PO}_{4}{ }^{3-}$ and $\mathrm{SiO}_{2}{ }^{4-}$ are both particle-associated nutrients with differing methods of solubilisation. Sediment systems contain much higher concentrations of $\mathrm{PO}_{4}{ }^{3-}$ than the overlying water column (Karl, 2014). As an anion, $\mathrm{PO}_{4}{ }^{3-}$ is known to bind to particles, such as aluminium hydroxides, manganese (Martins et al., 2014) and iron coated particles (Sundby et al., 1992) depending on surface charges (Bolan and Barrow, 1984). As a result, the potential free $\mathrm{PO}_{4}{ }^{3-}$ found in pore waters is generally low (Canfield et al., 2005). Release of $\mathrm{PO}_{4}{ }^{3-}$ from particles has been attributed to a change in water $\mathrm{pH}$, which triggers processes resulting in the electrostatic repulsion of the molecule from the particle (Borgnino et al., 2006). $\mathrm{SiO}_{2}{ }^{4-}$ reaches sediments in the form of diatom frustules, which sink passively to the seafloor, and are actively subducted by the feeding activities of the benthos. Within the sediments, $\mathrm{SiO}_{2}{ }^{4-}$ dissolves in the presence of oxygen and saturates porewaters, but also persists as tiny fragile particles (Dugdale and Wilkerson, 2001). A trawl event would break down the sediment pore structure and the proportion of particle-bound $\mathrm{PO}_{4}{ }^{3-}$ and siliceous particles released would be driven by electrostatic repulsion and dissolution mechanisms. The introduction of high concentrations of oxygen, changes in $\mathrm{pH}$ and vigorous mixing within the plume, would release the bound $\mathrm{PO}_{4}{ }^{3-}$ from particles and bring them into solution and facilitate the further breakdown of $\mathrm{SiO}_{2}{ }^{4-}$ (Dugdale and Wilkerson, 2001). At lower sampling heights, where particulate concentrations were particularly high $(25 \mathrm{~cm}$ and $35 \mathrm{~cm}$ ), it follows that the release would be substantially higher than at sampling heights $(>75 \mathrm{~cm})$ where particles were scarce. The release and breakdown of $\mathrm{NH}_{4}{ }^{+}, \mathrm{PO}_{4}{ }^{3-}$ and $\mathrm{SiO}_{2}{ }^{4-}$ may have been aided and augmented by the highly energetic and turbid conditions within trawl plumes, which collectively increased particle-particle interactions, thereby stimulating their physical degradation and dissolution, respectively.

\subsection{The relationship between PSD and dissolved nutrient concentrations}

The combined RDA analysis investigating the relationships between particle size categories and dissolved nutrient concentration indicated that $\mathrm{NO}_{3}{ }^{-}$and $\mathrm{NO}_{2}{ }^{-}$were correlated with high drag trawls (Fig. 8D), a trend which was supported by the positive increase in concentrations observed in the individual analyses presented in Fig. 6A-B. The RDA further supported the idea that $\mathrm{PO}_{4}{ }^{3-}$ and $\mathrm{SiO}_{2}{ }^{4-}$ are indeed particleassociated nutrients as the relative concentrations of both $\mathrm{SiO}_{2}{ }^{4-}$ and $\mathrm{PO}_{4}{ }^{3-}$ were aligned with the smaller particle size clusters (ranging from $2.50 \mu \mathrm{m}-156.90 \mu \mathrm{m}$; grain size classification: very coarse clay - very fine sand (Fig. 8D; Supplementary Table 1 ) and samples collected $\leq 35 \mathrm{~cm}$ of all drag categories (Fig. 8A \& B). The relative abundance of small particles was similar across different sampling heights (Fig. 4) however, absolute concentrations were higher in samples collected $\leq 35 \mathrm{~cm}$ from the seafloor than in samples collected $\geq 35 \mathrm{~cm}$ from the seafloor (Fig. 5), resulting in higher release and therefore higher concentrations of $\mathrm{PO}_{4}{ }^{3-}$ and $\mathrm{SiO}_{2}{ }^{4-}$. This strengthens the suggesting that the electrochemically/ electrostatically charged properties of smaller particles may have facilitated the release of $\mathrm{PO}_{4}{ }^{3-}$ and the dissolution of $\mathrm{SiO}_{2}{ }^{4-}$.

$\mathrm{NH}_{4}{ }^{+}$did not show any strong alignment with any level of drag or sampling level (Fig. 8D). This perhaps alludes to the potential for other $\mathrm{NH}_{4}{ }^{+}$sources than the seafloor to have influenced samples, including organisms in the water column captured in Niskin bottles or falling detritus.

\subsection{Implications for trawl gear design}

Individual and combined responses of particulate and pore-water dissolved nutrient release were explored with the aim of determining if trawl component design influences the biogeochemical impact of benthic trawling. Our results strongly indicated that the hydrodynamic drag related to the component diameter, rather than pressure associated with weight, determined the resuspended concentrations of particulates and nutrients. Combined analyses indicated that the resuspension of smaller particulates facilitated the release of $\mathrm{PO}_{4}{ }^{3-}$ and $\mathrm{SiO}_{2}{ }^{4-}$ and increasing drag was associated with higher concentrations of $\mathrm{NO}_{3}{ }^{-}$and $\mathrm{NO}_{2}{ }^{-}$, and so, reducing the drag and particulate load of a trawl plume would help to mitigate the disturbance to the system. In this case, particles were suspended further into the water column, increasing the potential for reduced light attenuation, while subsequently altering the particle compositions of a larger area of sediments upon settlement. In addition, the resuspension of nutrients would have led to changes in pore water $\mathrm{pH}$ by replacing highly concentrated solutions with fresh, oxidised sea water, as well as disturbing the established chemical gradients. Such changes would have extended the time required for the reestablishment of the electron gradient required for further benthic recycling. A shallower trawl plume, such as those produced by low drag components would reduce the disturbance effect on the surrounding area, as the spread and diffusion of particles is limited due to their proximity to the sea floor. Whether or not smaller gear components can be optimised in terms of fishing catch remains to be seen.

\section{Conclusions}

This study examined how different levels of drag and pressure associated with changing the size and weight of the trawl component affected the resuspension of particulate and dissolved material within different sections of the resulting trawl plume. Our analyses demonstrated that low-drag gear components would reduce the release of nutrients to the surface waters and lessen the particulate effects on the surrounding environment when compared to high drag components.

The particle size distribution of resuspended sediment changed with height above the seafloor, reflecting a filtration effect related to the hydrodynamic energy introduced by the trawl gear. We found a strong association between the size distribution of resuspended sediment and the relative concentrations of nutrients released into the water column. This suggests that the release of particle-associated nutrients, such as $\mathrm{PO}_{4}{ }^{3-}$ and $\mathrm{SiO}_{2}{ }^{4-}$, are dependent on the presence of smaller particulates, such as fine sands and clays. Trawl gear disturbance of sediments containing higher proportions of such electrostatically charged particulates would potentially release more $\mathrm{PO}_{4}{ }^{3-}$ and facilitate the breakdown of silica particles. Concentrations of $\mathrm{NO}_{2}{ }^{-}$and $\mathrm{NO}_{3}{ }^{-}$both increased as a function of drag, whereas $\mathrm{NH}_{4}{ }^{+}$concentrations increased as a function of pressure exerted on the seafloor and differed according to sampling height. These results suggest that nitrogen-based nutrients have less affinity to particle distributions and are more directly influenced by the forces exerted by the trawl gears themselves.

Our data clearly demonstrated that trawl gear design influenced the concentrations of resuspended sediments and nutrients and the heights to which they were transported. This suggests that the benthic disturbance of fishing gears could be minimised by designing them so that hydrodynamic drag and pressure force of the components in contact with the sea bed are reduced. It must also be recognised, however, that any design change also has the potential to alter the performance of a fishing gear, which hence may limit the range of suitable options.

\section{Data availability}

Data will be made available on request. 


\section{Declaration of competing interest}

The authors declare that they have no known competing financial interests or personal relationships that could have appeared to influence the work reported in this paper.

\section{Data availability}

Data will be made available on request.

\section{Acknowledgements:}

The authors would like to thank the staff and crew of the Marine Scotland survey vessel MRV Alba-Na-Mara and her crew for the work at sea which allowed these data to be collected. In addition, we would like to thank the Benthic Group at Marine Scotland Science for analysing the sediment grab samples. The authors would also like to thank the panel of four anonymous reviewers for their helpful comments on previous versions of this manuscript.

This work was supported by a NERC CASE PhD studentship (NE/ N007999/1).

\section{Appendix A. Supplementary data}

Supplementary data to this article can be found online at https://doi. org/10.1016/j.csr.2021.104628.

\section{References}

Agrawal, Y.C., Pottsmith, H.C., 2000. Instruments for particle size and settling velocity observations in sediment transport. Mar. Geol. 168, 89-114.

Agrawal, Y.C., Whitmire, A., Mikkelsen, O.A., Pottsmith, H.C., 2008. Light scattering by random shaped particles and consequences on measuring suspended sediments by laser diffraction. J. Geophys. Res.: Oceans 113, C04023. https://doi.org/10.1029/ 2007JC004403.

Amoroso, R.O., Pitcher, C.R., Rijnsdorp, A.D., McConnaughey, R.A., Parma, A.M., Suuronen, P., Eigaard, O.R., Bastardie, F., Hintzen, N.T., Althaus, F., Baird, S.J., Black, J., Buhl-Mortensen, L., Campbell, A.B., Catarino, R., Collie, J., Cowan Jr., J. H., Durholtz, D., Engstrom, N., Fairweather, T.P., Fock, H.O., Ford, R., Gálvez, P.A., Gerritsen, H., Góngora, M.E., González, J.A., Hiddink, J.G., Hughes, K.M., Intelmann, S.S., Jenkins, C., Jonsson, P., Kainge, P., Kangas, M., Kathena, J.N., Kavadas, S., Leslie, R.W., Lewis, S.G., Lundy, M., Makin, D., Martin, J., Mazor, T., Gonzalez-Mirelis, G., Newman, S.J., Papadopoulou, N., Posen, P.E., Rochester, W., Russo, T., Sala, A., Semmens, J.M., Silva, C., Tsolos, A., Vanelslander, B., Wakefield, C.B., Wood, B.A., Hilborn, R., Kaiser, M.J., Jennings, S., 2018. Bottom trawl fishing on the world's continental shelves. Proc. Natl. Acad. Sci. Unit. States Am. 115 (43), E10275-E10282. https://doi.org/10.1073/pnas.1802379115.

Balzer, W., 1984. Organic matter degradation and biogenic element cycling in a nearshore sediment (Kiel Bight). Limnol. Oceanogr. 29, 1231-1246.

Blott, S.J., Pye, K., 2012. Particle size scales and classification of sediment types based on particle size distributions: review and recommended procedures. Sedimentology 59, 2071-2096.

Bolan, N.S., Barrow, N.J., 1984. Modelling the effect of adsorption of phosphate and other anions on the surface charge of variable oxides. J. Soil Sci. 35, 273-281.

Borgnino, L., Avena, M., De Pauli, C., 2006. Surface properties of sediments from two Argentinean reservoirs and the rate of phosphate release. Water Res. 40, 2659-2666.

Canfield, D.E., Kristensen, E., Thamdrup, B., 2005. The phosphorus cycle. Adv. Mar. Biol. 48, 419-440.

Chassot, E., Melin, F., Le Pape, O., Gascuel, D., 2007. Bottom-up control regulates fisheries production at the scale of eco-regions in European seas. Mar. Ecol. Prog. Ser. 343, 45-55.

Churchill, J.H., 1989. The effect of commercial trawling on sediment resuspension and transport over the Middle Atlantic Bight continental shelf. Continent. Shelf Res. 9, 9 841-865.

Couceiro, F., Fones, G.R., Thompson, C.E.L., Statham, P.J., Sivyer, D.B., Parker, R., KelyGerren, B.A., Amos, C.L., 2013. Impact of resuspension of cohesive sediments at the Oyster Grounds (North Sea) on nutrient exchange across the sediment-water interface. Biogeochemistry 113, 37-52. https://doi.org/10.1007/s10533-012-97107.

DEFRA, 2012. Marine Strategy Part One: UK Initial Assessment and Good Environmental Status, pp. 1-163.

De Borger, E., Tiano, J., Braeckman, U., Rijnsdorp, A.D., Soetaert, K., 2021. Impact of bottom trawling on sediment biogeochemistry: a modelling approach. Biogeosciences 18, 2539-2557.

Depestele, J., Ivanovic, A., Degrendele, K., Esmaeili, M., Polet, H., Roche, M., Summerbell, K., Teal, L.R., Vanelslander, A., O’Neill, F.G., 2016. Measuring and assessing the physical impact of beam trawling. ICES J. Mar. Sci. 73 (1), 16-26. https://doi.org/10.1093/icesjms/fsv056.

Devol, A.H., Christensen, J.P., 1993. Benthic fluxes and nitrogen cycling in sediments of the continental margin of the eastern North Pacific. J. Mar. Res. 51, 345-372.

Dounas, C.G., 2006. A new apparatus for the direct measurement of the effects of otter trawling on benthic nutrient release. J. Exp. Mar. Biol. Ecol. 339 (2), 251-259.

Dounas, C., Davies, I.M., Triantafyllou, G., Koulouri, P., Petihakis, G., Arvanitidis, C., Sourlatzis, G., Eleftheriou, A., 2007. Large-scale impacts of bottom trawling on shelf primary productivity. Continent. Shelf Res. 27 (17), 2198-2210. https://doi.org/ 10.1016/j.csr.2007.05.006.

Dugdale, R.C., Wilkerson, F.P., 2001. Sources and fates of silicon in the ocean: the role of diatoms in the climate and glacial cycles. Sci. Mar. 65, 141-152.

Durrieu de Madron, X., Ferré, B., Le Corre, G., Grenz, C., Conan, P., Pujo - Pay, M., Buscail, R., Bodiot, O., 2005. Trawling - induced resuspension and dispersal of muddy sediments and dissolved elements in the Gulf of Lion (NW Mediterranean) Continent. Shelf Res. 25, 2387-2409.

Eigaard, O.R., Bastardie, F., Breen, M., Dinesen, G.E., Hintzen, N.T., Laffargue, P., Mortensen, L.O., Nielsen, J.R., Nilsson, H., O'Neill, F.G., Polet, H., Reid, D.G., Sala, A., Sköld, M., Smith, C., Thomas, K., Sørensen, T.K., Zengin, M., Rijnsdorp, A. D., 2016. Estimating seabed pressure from demersal trawls, seines, and dredges based on gear design and dimensions. ICES J. Mar. Sci. 73, 27-43. https://doi.org/ 10.1093/icesjms/fsv099.

Eigaard, O.R., Bastardie, F., Hintzen, N.T., Buhl-Mortensen, L., Buhl-Mortensen, P., Catarino, R, Dinesen, G.E., Egekvist, J., Fock, H.O., Geitner, K., Gerritsen, H.D., González, M.M, Jonsson, P., Kavados, S, Laffargue, P., Lundy, M., GonzalezMirelis, G., Nielsen, J.R., Papadopoulou, N., Posen, P.E., Pulcinella, J., Russo, T., Sala, A., Silva, C., Smith, C.J., Vanelslander, B., Rijnsdorp, A.D., 2017. The footprint of bottom trawling in European waters: distribution, intensity, and seabed integrity. ICES 74 (3), 847-865. https://doi.org/10.1093/icesjms/fsw194.

Fenchel, T., Jorgensen, B., 1977. Detritus food chains of aquatic ecosystems: the role of bacteria. Adv. Microb. Ecol. 366, 99-103.

Hale, R., Godbold, J.A., Sciberras, M., Dwight, J., Wood, C., Hiddink, J.G., Solan, M., 2017. Mediation of post-disturbance shelf sea sediment communities. Biogeochemistry 135 (1-2), 121-133.

Hebbali, A., 2020. Olsrr: tools for building OLS regression models. R. pack.vers. 0.5.3. https://CRAN.R-project.org/package=olsrr.

Henley, W.F., Patterson, M.A., Neves, R.J., Lemly, A.D., 2010. Effects of sedimentation and turbidity on lotic food webs: a concise review for natural resource managers. Rev. Fish. Sci. 125-139.

Karl, D.M., 2014. Microbially mediated transformations of phosphorus in the sea: new views of an old cycle. Ann. Rev. Mar. Sci. 6, 279-337.

Legendre, P., Gallagher, E.D., 2001. Ecologically meaningful transformations for ordination of species data. Oecologica 129, 271-280.

Lennon, J.T., Cottingham, K.L., 2008. Microbial productivity in variable resource environments. Ecology 89, 1001-1014.

Martins, G., Peixoto, L., Brito, A.G., Nogueira, R., 2014. Phosphorus - iron interactions in sediments: can an electrode minimize phosphorus release from sediments? Rev. Environ. Sci. Biotechnol. 13 (3), 265-275.

Mayor, D.J., Solan, M., 2011. Complex interactions mediate the effects of fish farming on benthic chemistry within a region of Scotland. Environ. Res. 111, 5 635-642.

Mayor, D.J., Gray, N.B., Elver-Evans, J., Midwood, J.A., Thornton, B., 2013. Metalmacrofauna interactions determine microbial community structure and function in copper contaminated sediments. PLoS One 8 (5), e64940. https://doi.org/10.1371/ journal.pone.0064940.

Nilsson, H.C., Rosenberg, R., 2003. Effects on marine sedimentary habitats analysed by sediment profile imagery. J. Exp. Mar. Biol. Ecol. 285-286, 453-463.

O'Neill, F.G., Summerbell, K., 2011. The mobilisation of sediment by demersal otter trawls. Mar. Pollut. Bull. 62, 5 1088-1097.

O'Neill, F.G., Summerbell, K., 2016. The hydrodynamic drag and mobilisation of sediment into the water column of towed fishing gear components. J. Mar. Syst. 164, 76-84.

O'Neill, F.G., Ivanović, A., 2016. The physical impact of towed demersal fishing gears on soft sediments. ICES J. Mar. Sci. 73, 5-14.

O'Neill, F.G., Summerbell, K., Ivanovic, A., 2018. The contact drag of towed demersal fishing gear components. J. Mar. Syst. 177, 39-52.

Oksanen, J., Blanchet, F.G., Kindt, R., 2013. Package "vegan". Ecol. Packag.

Pauly, D., Christensen, V., Guénette, S., Pitcher, T.J., Sumaila, U.R., Walters, C.J., Watson, R., Zeller, D., 2002. Towards sustainability in world fisheries. Nature 818, 689-695.

Pilskaln, C.H., Churchill, J.H., Mayer, L.M., 1998. Resuspension of sediment by bottom trawling in the Gulf of Maine and potential geochemical consequences. Conserv. Biol. 12, 6 1223-1229.

Pinheiro, J., Bates, D., DebRoy, S., Sarkar, D., R Core Team, 2017. nlme: linear and nonlinear mixed effects models. R Packag. $3^{\text {rd }}$ edn 1-336.

R Core team. R, 2014. A Language and Environment for Statistical Computing. R Fed. Stat. Comput. Vienna, Austria.

Rijnsdorp, A., Eigaard, O.R., Kenny, A., Hiddink, J.G., Hamon, K., Piet, G., Sala, A., Nielsen, R., Polet, H., Laffargue, P., Zengin, M., Gregerson, O., 2017. Assessing and mitigating of bottom trawling. Final BENTHIS project Report (Benthic Ecosystem Fisheries Impact Study). Seventh Framework Programme, pp. 3-27.

Rijnsdorp, A.D., Depestele, J., Eigaard, O.R., Ivanović, A., O'Neill, F.G., 2021. Sediment mobilization by bottom trawls: a model approach applied to the Dutch North Sea beam trawl fishery. ICES (Int. Counc. Explor. Sea) J. Mar. Sci. https://doi.org/ 10.1093/icesjms/fsab029.

Sciberras, M., Hiddink, J.G., Jennings, S., Szotek, C.L., Hughes, K.M., Kneafsey, B., Clarke, L.J., Ellis, N., Rijnsdorp, A., McConnaughey, R.A., Hilborn, R., Collie, J.S., 
Pitcher, C.R., Amoroso, R.O., Parma, A.M., Suuronen, P., Kaiser, M.J., 2018 Response of fauna to experimental bottom fishing: a global meta-analysis. Fish Fish. https://doi.org/10.1111/faf.12283.

Smith, C.J., Rumohr, H., Karakassis, I., Papadopoulou, K., 2003. Analysing the impact of bottom trawls on sedimentary seabeds with sedimentary profile imegary, 286, 479-496.

Sundby, B., Gobeil, C., Silverberg, N., Mucci, A., 1992. The phosphorus cycle in coastal marine sediments. Limnol. Oceanogr. 37 (6), 11-1145.

Tiano, J., Whitbaard, R., Bergman, M.J.N., van Rijswijk, P., Tramper, A., van Oevelen, D., Soetaert, K., 2019. Acute impacts of bottom trawl gears on benthic metabolism and nutrient cycling. ICES (Int. Counc. Explor. Sea) J. Mar. Sci. 76, 6 1917-1930.

Trimmer, M., Petersen, J., Sivyer, D.B., Mills, C., Young, E., Parker, E.R., 2005. Impact of long-term benthic trawl disturbance on sediment sorting and biogeochemistry in the North Sea. Mar. Ecol. Prog. Ser. 298, 79-94.

Wengrove, M.E., Foster, D.L., Kalnejais, L.H., Percuoco, V., Lippmann, T.C., 2015. Field and Laboratory Observations of Bed Stress and Associated Nutrient Release in a Tidal Estuary, 161, pp. 11-24.

Wentworth, C.K., 1922. A scale of grade and class terms for clastic sediments. J. Geol. 5, 377-392. 